\title{
Open-Circuit Field Prediction of Interior Permanent-Magnet Motor Using Hybrid Field Model Accounting for Saturation
}

\author{
Zhaokai $\mathrm{Li}^{1,2}$, Xiaoyan Huang ${ }^{1}$, Lijian $\mathrm{Wu}^{1}$, Teng Long ${ }^{2}$, Bowen $\mathrm{Shi}^{3}$ and He Zhang ${ }^{3}$ \\ ${ }^{1}$ Zhejiang Provincial Key Laboratory of Electrical Machine Systems, College of Electrical Engineering, Zhejiang University, \\ Hangzhou, 310027, China \\ ${ }^{2}$ Department of Engineering, University of Cambridge, Cambridge, CB30FA, UK \\ ${ }^{3}$ Power Electronics, Machines, and Control Group, University of Nottingham, Ningbo, 315100, China
}

\begin{abstract}
A hybrid field model (HFM) based on the combination of magnetic equivalent circuit (MEC) and exact conformal mapping (ECM) is developed to calculate the open-circuit field of interior permanent-magnet (IPM) motor. In the proposed HFM, the IPM and iron saturation is transformed into equivalent current on the rotor surface and stator bore. ECM can calculate the air-gap field analytically using the equivalent current. Once the air-gap field is obtained, the MEC in the iron region can be solved and gives the new value of equivalent current, which forms a calculation loop. Hence, iterative solving process is required to determine the equivalent current and iron permeability in the rotor and stator. In order to verify the proposed model, both finite element (FE) analysis and experiment are performed on IPM motors with V-type rotor and conventional "_" type rotor. Their results demonstrate the high accuracy of HFM.
\end{abstract}

Index Terms-Magnetic equivalent circuit, complex permeance, saturation effect, interior permanent magnet machine

\section{INTRODUCTION}

$\mathrm{T}$ HE INTERIOR permanent-magnet (PM) motors are very attractive in many industrial application such as electrical traction vehicles due to its high power density, high efficiency and wide speed range. In order to analyze the field distribution of IPM motor, finite element method (FEM), MEC and some analytical models are used in the initial design and optimization process. The high accuracy of FEM makes it widely-used to analyze the PM motors as well as validate the analytical model of PM motors [1]-[6]. However, it is time-consuming. MEC is simple and fast when it divides the motor into several simple regions and calculates the major flux distribution [6]-[8]. As the number of magnetic reluctance representing the division region increases, the field prediction will be more accurate but the calculation time will be longer as well [9]-[10].

Analytical models such as winding function theory and conformal mapping method show their advantage in the air-gap field prediction of IPM motors. Qi et al. employed the winding function theory and the rotor MMF function to predict the armature reaction field for IPM motor [2]. Mirazimi et al. regarded the embedded magnets as virtual equivalent surfacemounted permanent magnet (SPM) and calculated the air-gap field based on conformal mapping considering both slotting effect and rotor saliency effect [3]. Chen et al. used modified MMF of stator and rotor magnetic potentials to calculate inductance, which is suitable for IPM motors with fractional slot concentrated windings [11]. However, these models in [2][3], [11] neglects the iron saturation of IPM motor and therefore introduces errors. In order to consider the bridge saturation, Lim et al. used simple MEC to calculate the air-gap fluxdensity and then employed conformal mapping to describe the slotting effect [4]. Zhang et al. combined the MEC with subdomain technique through the coupling boundary conditions on the rotor surface and predicted the open-circuit field of multilayer interior permanent magnet machines [5]. Nevertheless, these models only account for the iron saturation in the bridge iron
[4]-[5].

The conception of virtual SPM motor is useful for the analysis of IPM motor [3]-[5]. Akiki et al. proposed a saturated analytical model based on Ampere's theorem and flux conservation law, which considers both stator and rotor saturation [12]. Farshadnia formulated the saturation level at different rotor regions using the rotor geometry and the nonlinear B-H curve, and obtained the equivalent air-gap function to calculate the air-gap field of IPM motors with the non-homogeneously saturated rotor [13]. In order to fully represent the saturation effect, MEC can be used to accurately describe the stator and rotor saturation. In the air-gap region, unlike the traditional MEC with dynamic air reluctance, the analytical model based on conformal mapping is employed, which can accurately account for the slotting effect. Similar model which combined the conformal mapping with MEC was proposed in [14]-[18], but they all associated with SPM motors, which are much different from IPM motor.

In this paper, the HFM which predicts the air-gap field based on exact conformal mapping and accounts for the iron saturation using MEC is proposed to calculate the open-circuit electromagnetic performance of IPM motors. The coupling of MEC and conformal mapping on the stator bore and rotor surface is established through virtual equivalent current. The equivalent current is calculated from magnetic potential distribution in the MEC and serves as the flux source to produce magnetic field in the air-gap. The exact conformal mapping can accurately describe the slotting effect and is calculated only once in the IPM motors, which saves much computation time. Both FE analysis and experiment results demonstrate the high accuracy of HFM.

\section{HYBRID FIELD MODEL}

The keypoint of HFM is to transform the PM and iron saturation into the virtual equivalent current so that the analytical model based on conformal mapping can accurately calculate the air-gap field. Fig. 1 shows the equivalent current 
distribution in the stator, V-type rotor, and conventional "_" type rotor of IPM motor, which accounts for the iron saturation. Hence the iron permeability is regarded as infinite and the analytical model can be used to solve the air-gap field distribution.

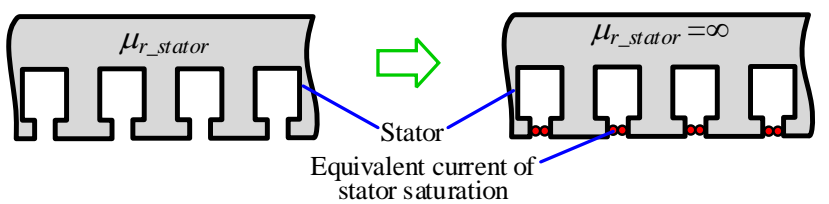

(a)

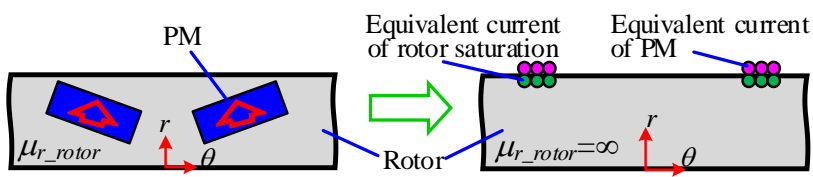

(b)

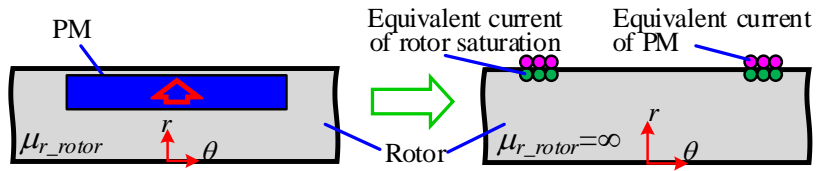

(c)

Fig. 1 Virtual equivalent current distribution considering sat uration effect in the IPM motor: (a) stator, (b) V-type rotor, and (c) conventional “_” type rotor.

\section{A. Magnetic Equivalent Circuit for Stator and Rotor}

In the HFM, MEC is used to show magnetic potential distribution of stator and rotor. Fig. 2 illustrates the general magnetic reluctance distribution in the IPM motor with V-type rotor and conventional "." type rotor. According to the Kirchhoff's current law, magnetic potential $\mathbf{V}$ in the iron region can be solved as long as the air-gap flux flowing into the stator and rotor is obtained [18].

$$
f(\mathbf{V})=\mathbf{A} \mathbf{\Lambda} \mathbf{A}^{\mathbf{T}} \mathbf{V}-\mathbf{A} \boldsymbol{\Phi}=0
$$

where $\boldsymbol{\Phi}$ cons is ts of $\varphi_{r j}$ and $\varphi_{s j}$ for the fluxes into rotor and stator. $\mathbf{A}$ and $\boldsymbol{\Lambda}$ are the incidence matrix and branch permeance matrix, respectively. Once the solution of MEC is given, the virtual equivalent current can be calculated from

$$
\left\{\begin{array}{l}
i_{r a i}+i_{m a i}=-\left(V_{i+1}-V_{i}\right) \\
i_{r b i}+i_{m b i}=-\left(V_{i+2}-V_{i+1}\right) \\
i_{r c i}+i_{m c i}=-\left(V_{i+3}-V_{i+2}\right) \\
i_{r d i}+i_{m d i}=-\left(V_{i+4}-V_{i+3}\right) \\
i_{s j}=-\left(V_{j+1}-V_{j}\right)
\end{array}\right.
$$

where $i_{r a i}, i_{r b i} i_{r c i}$, and $i_{r d i}$ are the equivalent current of saturation on the rotor surface corresponding to the magnetic bridge region while $i_{m a i}, i_{m b i}, i_{m c i}$, and $i_{m d i}$ are the equivalent current of PM on the same place ( $i$ is the index of pole number, $i=1,2, \cdots$, $2 p) . i_{s j}$ is the equivalent current of saturation on the stator slot opening ( $j$ is the slot index, $j=1,2, \cdots, Q_{s}$ ). $V_{i}$ and $V_{j}$ represent magnetic potential on the rotor surface and stator bore. They are all specified in Fig. 2. Hence, the total equivalent current can also be expressed in the matrix form.

$$
\begin{aligned}
I_{e q} & =\left[i_{e q 1}\left(r_{c 1}, \theta_{c 1}\right), \cdots, i_{e q k}\left(r_{c k}, \theta_{c k}\right), \cdots, i_{e q N_{c c}}\left(r_{c N_{c c}}, \theta_{c N_{c c}}\right)\right]^{\mathrm{T}} \\
& =\mathbf{C V}
\end{aligned}
$$

where $i_{e q k}$ represents the equivalent current at the position $\left(r_{c k}\right.$, $\left.\theta_{c k}\right)$ in the polar coordinate and consis ts of $i_{r a i}, i_{r b i}, i_{r c i}, i_{r d i}, i_{m a i}$, $i_{m b i}, i_{m c i}, i_{m d i}$, and $i_{s j} . N_{c c}$ is the number of equivalent current, and $\mathbf{C}$ is the coefficient matrix which is calculated from (2).

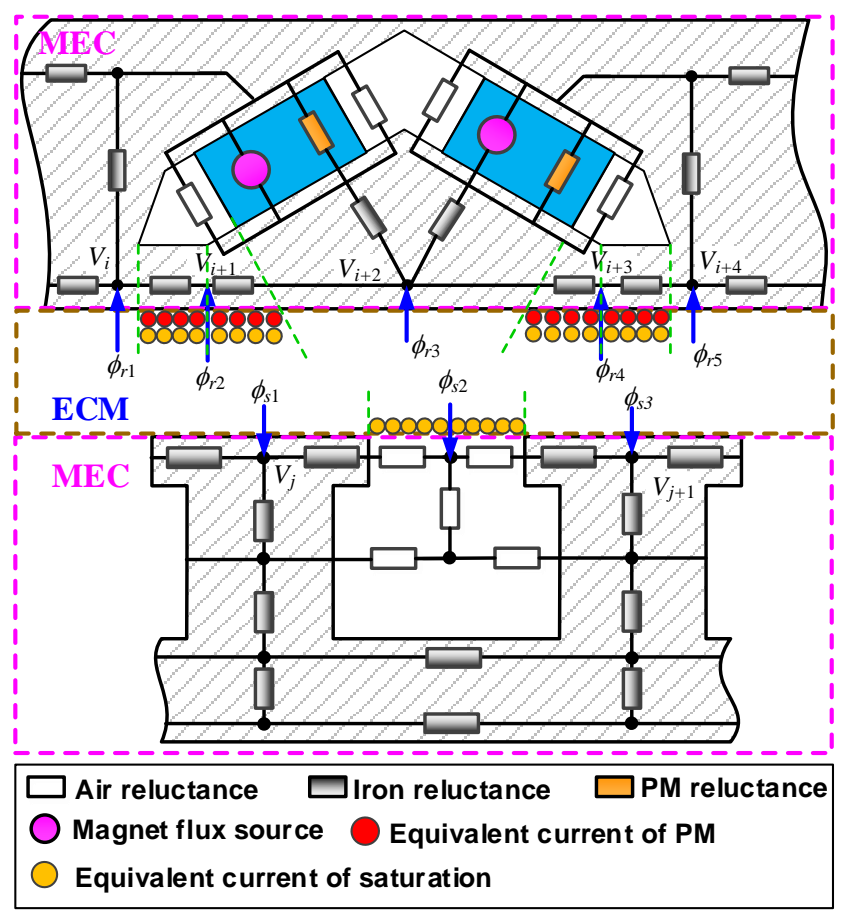

(a)

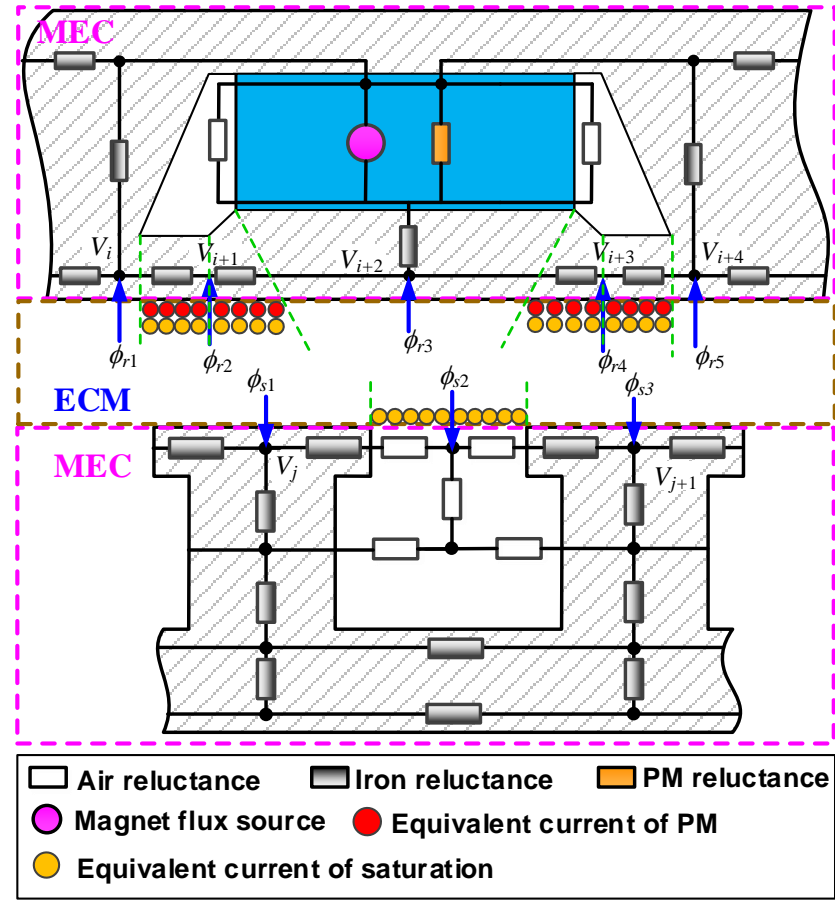

(b)

Fig. 2 Magnetic equivalent circuit in the IPM motor with (a) V-typerotorand (b) conventional "." type rotor.

\section{B. Exact Conformal Mapping for Air-gap Region}

EMC is widely used to predict the slotted air-gap field in the SPM motors with high accuracy. However, it is very timeconsuming as it is calculated at every rotor position [19]-[20]. Unlike SPM motors, in the proposed HFM for analyzing IPM 
motors, EMC is only calculated at the initial rotor position and remains unchanged because the position of equivalent current is fixed in the air-gap region. Therefore, it will save much computation while guaranteeing the high accuracy. Three transformations are performed to mapping the slotted air-gap region to a slotless region [19]-[20], as shown in Fig. 3. The first transformation converts the original slotted $\mathrm{S}$ plane to $\mathrm{Z}$ plane using logarithmic function, Fig 3(a)-(b).

$$
S=r e^{j \theta}=e^{Z}
$$

The second transformation is based on Schwarz-Christoffel(SC) mapping using (5) [21], Fig 3(b)-(c).

$$
Z=A_{0} \int \prod_{k=1}^{n-1}\left(W-w_{k}\right)^{-\frac{\beta_{k}}{\pi}} d W+C_{0}
$$

where $A_{0}, C_{0}, w_{1}, \cdots, w_{n-1}, \beta_{1}, \cdots, \beta_{n-1}$ are the parameters of SC transformation. As these parameters cannot be computed analytically, SC Toolbox in the Matlab is developed to numerically obtain these values. Theoretically, it can transform the slotted air region with arbitrary slot shape in $\mathrm{Z}$ plane into rectangle in $\mathrm{W}$ plane. However, it will cost much computation time while having negligible influence on the air-gap field. Hence, the slot shape is simplified without tooth-tip, Fig 3(a). The last transformation is shown in (6) and Fig 3(c)-(d), which converts the rectangle in the $\mathrm{W}$ plane to annular domain in the $\Psi$ plane and the scalar magnetic potential in the annulus is given by Hague [22].

$$
W=\frac{\Delta x}{2}\left(1+j \frac{\log (\psi)}{\pi}\right)+j \frac{\Delta y}{2}
$$

where $\Delta x$ and $\Delta y$ are the width and height of canonical rectangle in the $W$ domain.

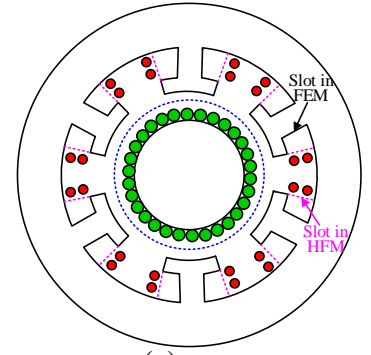

(a)

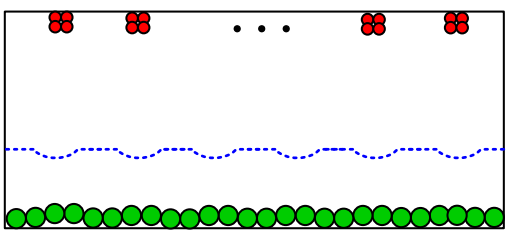

(c)

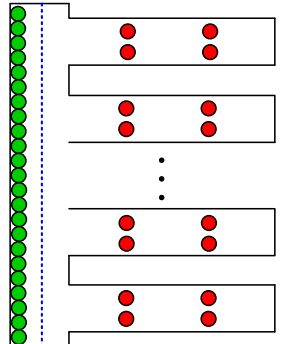

(b)

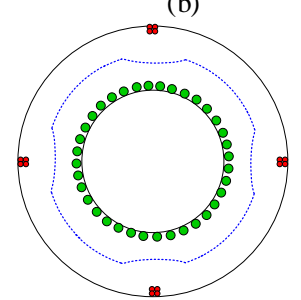

(d)
Fig. 3 The infinitely permeable IPM motor with equivalent current in(a)Splane, (b) Z plane, (c) W plane, and (d) $\Psi$ plane.

According to Hague's equation, the radial and tangential airgap field produced by the current $i_{e q k}$ at the position $\left(R_{c \psi}, \alpha_{c \psi}\right)$ in the annular domain of $\Psi$ plane can be expressed as .

$$
\begin{aligned}
B_{r \psi k}\left(r_{\psi}, \alpha_{\psi}\right)= & \frac{\mu_{0} i_{e q k}\left(R_{c \psi}, \alpha_{c \psi}\right)}{2 \pi}\left\{\delta_{\psi}+\sum_{n=1}^{\infty} \frac{R_{s \psi}^{n}}{R_{c \psi}^{n}}\left(\frac{R_{s \psi}^{2 n}+R_{c \psi}^{2 n}}{R_{r \psi}^{2 n}-R_{s \psi}^{2 n}} .\right.\right. \\
& \left.\left.\frac{r_{\psi}{ }^{n-1}}{R_{s s}^{n}}+\frac{R_{c \psi}^{2 n}+R_{r \psi}^{2 n}}{R_{r \psi}^{2 n}-R_{s \psi}^{2 n}} \cdot \frac{R_{s \psi}^{n}}{r_{\psi \psi}{ }^{n+1}}\right) \sin \left[n\left(\alpha_{\psi}-\alpha_{c \psi}\right)\right]\right\} \\
B_{t \psi k}\left(r_{\psi}, \alpha_{\psi}\right)= & \frac{\mu_{0} i_{e q k}\left(R_{c \psi}, \alpha_{c \psi}\right)}{2 \pi r_{\psi}}\left\{\gamma_{\psi}+\sum_{n=1}^{\infty} \frac{R_{s \psi}^{n}}{R_{c \psi}^{n}}\left(\frac{R_{s \psi}^{2 n}+R_{c \psi}^{2 n}}{R_{r \psi}^{2 n}-R_{s \psi}^{2 n}} .\right.\right. \\
& \left.\left.\frac{r_{\psi}{ }^{n}}{R_{s \psi}^{n}}-\frac{R_{c \psi}^{2 n}+R_{r \psi}^{2 n}}{R_{r \psi}^{2 n}-R_{s \psi}^{2 n}} \cdot \frac{R_{s \psi}^{n}}{r_{\psi}{ }^{n}}\right) \cos \left[n\left(\alpha_{\psi}-\alpha_{c \psi}\right)\right]\right\}
\end{aligned}
$$

where $R_{r \psi}$ and $R_{s \psi}$ are the radius of rotor surface and stator bore in the $\Psi$ plane. $\gamma_{\psi}$ and $\delta_{\psi}$ can be expressed as (9) and (10), respectively.

$$
\begin{aligned}
& \gamma_{\psi}=\left\{\begin{array}{lc}
\sum_{n=1}^{\infty}\left\{\frac{r_{\psi}{ }^{n}}{R_{c \psi}^{n}} \cos \left[n\left(\alpha_{\psi}-\alpha_{c \psi}\right)\right]\right\}, & R_{r \psi} \leq r_{\psi}<R_{c \psi} \\
-1, & r_{\psi}=R_{c \psi} \\
-1-\sum_{n=1}^{\infty}\left\{\frac{R_{c \psi}^{n}}{r_{\psi}{ }^{n}} \cos \left[n\left(\alpha_{\psi}-\alpha_{c \psi}\right)\right]\right\}, & R_{c \psi}<r_{\psi} \leq R_{s \psi}
\end{array}\right. \\
& \delta_{\psi}=\left\{\begin{array}{l}
\sum_{n=1}^{\infty}\left\{\frac{r^{n-1}}{R_{c \psi}^{n}} \sin \left[n\left(\alpha_{\psi}-\alpha_{c \psi}\right)\right]\right\}, R_{r \psi} \leq r_{\psi}<R_{c \psi} \\
0, r_{\psi}=R_{c \psi} \\
\sum_{n=1}^{\infty}\left\{\frac{R_{c \psi}^{n}}{r^{n+1}} \sin \left[n\left(\alpha_{\psi}-\alpha_{c \psi}\right)\right]\right\}, R_{c \psi}<r_{\psi} \leq R_{s \psi}
\end{array}\right.
\end{aligned}
$$

As conformal maps preserve scalar potentials, the magnetic field in the original $\mathrm{S}$ plane can be obtained from the conformal mapping function (4)-(6) and the magnetic field in the $\Psi$ plane (7)-(10) [19]-[20].

$$
\begin{aligned}
B_{s k} & =\left(B_{r s k}+j B_{t s k}\right) \\
& =B_{\psi}\left(\frac{1}{\frac{\partial w}{\partial \psi}}\right)^{*}\left(\frac{1}{\frac{\partial z}{\partial w}}\right)^{*}\left(\frac{\partial z}{\partial s}\right)^{*} \\
& =\left(B_{r \psi k}+j B_{t \psi k}\right)\left(\frac{2 \pi}{j \Delta x} r_{\psi} e^{j \alpha_{\psi \psi}}\right)^{*}\left(\frac{1}{\text { evaldiff }(f, w)}\right)^{*}\left(\frac{1}{r e^{j \theta}}\right)^{*}
\end{aligned}
$$

where evaldiff( $(, w)$ is the Matlab Command in the SC Toolbox [21]. It is noted that $B_{s k}$ only represents the air-gap field produced by the $k$ th equivalent current $i_{e q k}$. Based on the principle of superposition, the total radial and tangential magnetic field can be calculated from

$$
\begin{aligned}
B_{r s} & =\sum_{k=1}^{N_{c c}} B_{r s k}\left(i_{e q k}\right)=\sum_{k=1}^{N_{c c}} g_{k} \cdot i_{e q k}=\mathbf{G}_{\mathbf{s}} \mathbf{I}_{\mathbf{e q}} \\
B_{t s} & =\sum_{k=1}^{N_{c c}} B_{t s k}\left(i_{e q k}\right)=\sum_{k=1}^{N_{c c}} h_{k} \cdot i_{e q k}=\mathbf{H}_{\mathbf{s}} \mathbf{I}_{\mathbf{e q}}
\end{aligned}
$$

where $g_{k}$ and $h_{k}$ are calculated from (4)-(11) while $\mathbf{G}_{\mathbf{s}}$ and $\mathbf{H}_{\mathbf{s}}$ are the matrix form of $g_{k}$ and $h_{k}$. 


\section{Calculation Process of Equivalent Current}

In order to solve the magnetic field distribution in both air and iron region, it is required to solve the MEC and EMC simultaneously. Hence it is necessary to combine MEC with EMC through the equivalent current. In the MEC, the flux flowing into the iron region (e.g., $\varphi_{r 1}, \varphi_{r 2}, \cdots$ and $\varphi_{s 1}, \varphi_{s 2}, \cdots$ in Fig. 2) can be derived from the integration of radial flux density using (12).

$$
\begin{aligned}
\varphi_{a i} & =R_{a} l_{e f} \int_{\beta_{a i 1}}^{\beta_{a i 2}} B_{r s a} d \alpha=R_{a} l_{e f}\left(\int_{\beta_{a i 1}}^{\beta_{a i 2}} \mathbf{G}_{\mathbf{s}} d \alpha\right) \mathbf{I}_{\mathbf{e q}} \\
& =R_{a} l_{e f} \mathbf{K}_{a i} \mathbf{I}_{\mathbf{e q}}=R_{a} l_{e f} \mathbf{K}_{a i} \mathbf{C V}
\end{aligned}
$$

where $a=s$ for stator and $a=r$ for rotor, $i$ is the index of integration interval. $l_{e f}, R_{r}$, and $R_{s}$ are the active length, radius of rotor surface and stator bore, respectively. The bounds of integration $\beta_{a i 1}$ and $\beta_{a i 2}$ can be determined by the position of slots or magnet and motor dimension. Thus, as the matrix form of $\varphi_{a i}, \boldsymbol{\Phi}$ can be expressed as

$$
\begin{aligned}
\mathbf{\Phi} & =\left[\varphi_{s 1}, \cdots, \varphi_{r 1}, \cdots\right]^{\mathrm{T}} \\
& =R_{a} l_{e f}\left[\mathbf{K}_{s 1} \mathbf{C}, \cdots, \mathbf{K}_{r 1} \mathbf{C}, \cdots\right]^{\mathrm{T}} \mathbf{V}
\end{aligned}
$$

Combining (1) with (15), the magnetic potential $\mathbf{V}$ in the HFM can be iteratively solved in only one loop. Then the equivalent current can be obtained to predict air-gap field of the IPM motor. Fig. 4 shows a flowchart to determine equivalent current and electromagnetic performance of the IPM motors.

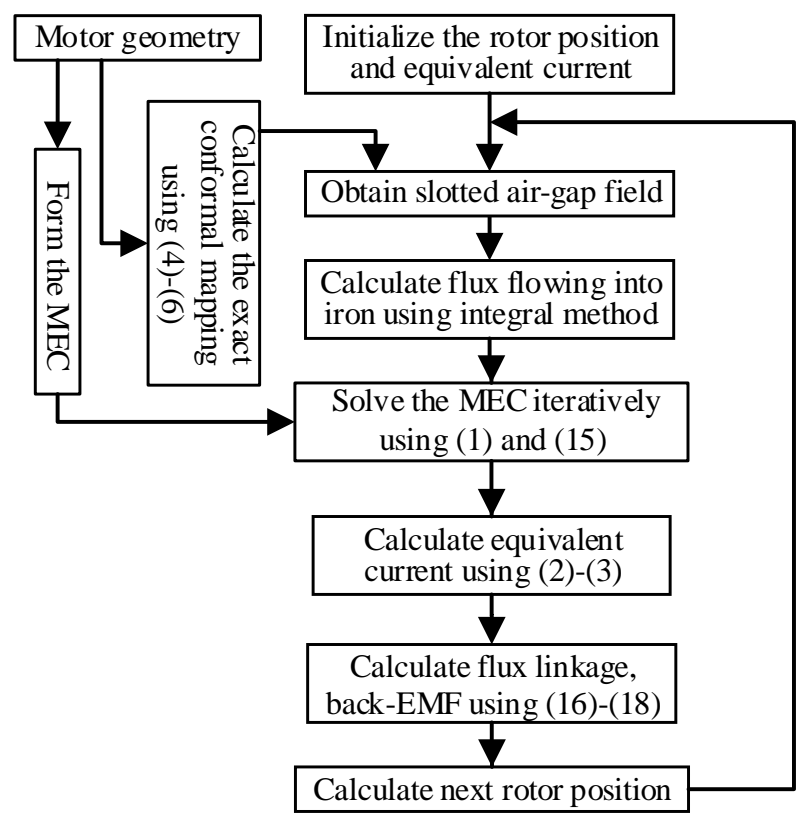

Fig. 4 Flowchart of HFM for predicting the electromagnetic performance of the IPM motor.

The flux linkage of IPM motor can be calculated from the flux distribution in the MEC [18].

$$
\psi_{p h}(t)=N_{c} \sum_{i=1}^{\kappa}\left[\varphi_{i}(t)+\Psi_{l i}(t)\right]
$$

where $N_{c}$ is the turns of coil and $\kappa$ is the coil number belonging to one phase. $\Psi_{l i}(t)$ is the leakage flux in the slots, which can be obtained from MEC solution. $\varphi_{i j}$ is the main flux and can be calculated from

$$
\varphi_{i}(t)=R_{s} l_{e f} \int_{\beta_{s l j}}^{\beta_{s j}} B_{r s}\left(\alpha, R_{s}, t\right) d \alpha
$$

where $\beta_{s 2 j}$ and $\beta_{s 1 j}$ are determined by the slot position and coil pitch. Hence the back-EMF is obtained from the time derivative of flux linkage.

$$
E_{p h}=-\frac{d \psi_{p h}}{d t} \quad p h=A, B, C
$$

\section{FE AND EXPERIMENT AL VALIDATION}

In order to validate the HFM, two 8-pole/36-slot IPM motors with V-type rotor and two 8-pole/24-slot IPM motors with conventional "-" type rotor are investigated by HFM and FEM. It is noted that the stator yoke of 8-pole/36-slot motor is set to 17.6mm (Motor A) and $7.6 \mathrm{~mm}$ (Motor B), respectively, while the tooth width of 8-pole/24-slot motor is set to $12 \mathrm{~mm}$ (Motor C) and $8 \mathrm{~mm}$ (Motor D), respectively. Such design makes IPM motors at different saturation level and therefore demonstrates the effectiveness of the proposed model. The experiment has been carried out on Motor A to verify the accuracy of HFM. Fig. 5 gives the flux density distribution of IPM motor while Fig. 6 shows the prototype IPM motor for experimental validation. The major parameters of these four motors are given in TABLE I. The BH curves of the electrical steel for these IPM motors are shown in Fig. 7.

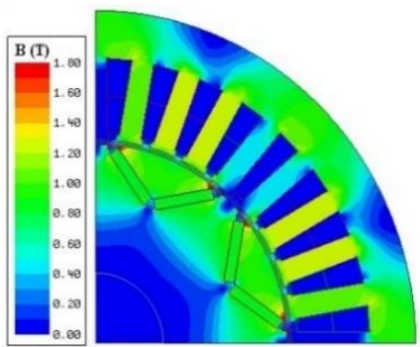

(a)

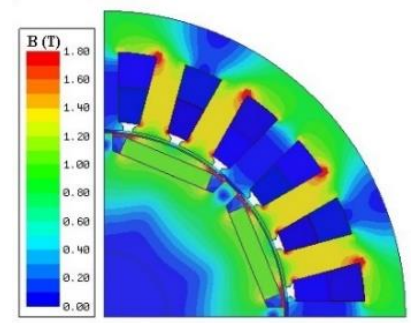

(c)

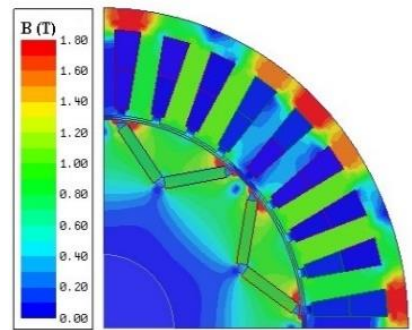

(b)
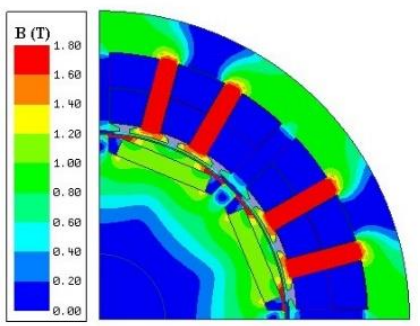

(d)
Fig. 5. Investigated IPM machines: (a) Motor A (b) Motor B, (c)MotorC, and (d) Motor D.

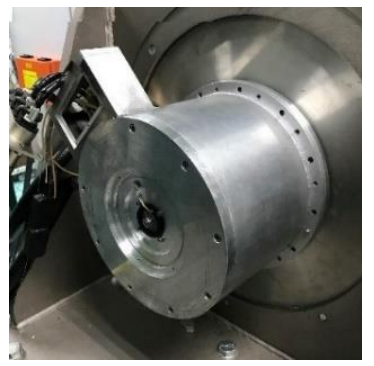

Fig. 6 Experimental 8-pole/36-slot IPM motor(Motor A). 
TABLE I

MAIN PARAMETERS OF THE IPM MOTORS

\begin{tabular}{llll}
\hline \hline Parameter & 8-pole/36-slot & 8-pole/24-slot & \\
& & & \\
\hline Stator outer radius & 122.5 & 122.5 & $\mathrm{~mm}$ \\
Magnet remanence & 1.22 & 1.26 & $\mathrm{~T}$ \\
Relative recoil permeability & 1.01 & 1.07 & $\mathrm{rpm}$ \\
Rated speed & 2800 & 3000 & \\
Number of pole pairs & 4 & 4 & \\
Lamination material & $\mathrm{M} 235-35 \mathrm{~A}$ & WG35WW300 & \\
\hline \hline
\end{tabular}

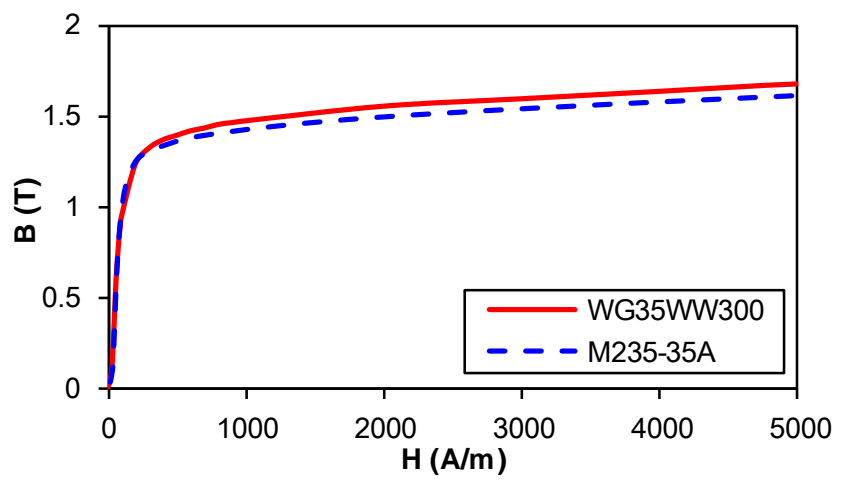

Fig. $7 \mathrm{BH}$ curves of the electrical steel used in the analyzed IPM motor.

Figs. 8-9 show the comparis on of radial and tangential airgap field predicted by HFM and FEM for the four motors. All of the HFM predicted field agree well with FEM results under unsaturated or saturated open-circuit condition. Besides, it can be seen that iron saturation will decrease the amplitude of magnetic field and therefore it is necessary to considering the saturation effect for the initial design of IPM motors.

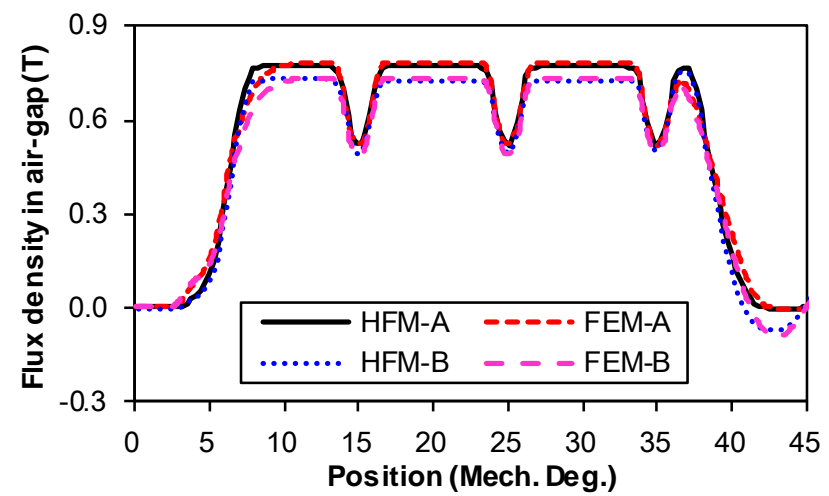

(a)

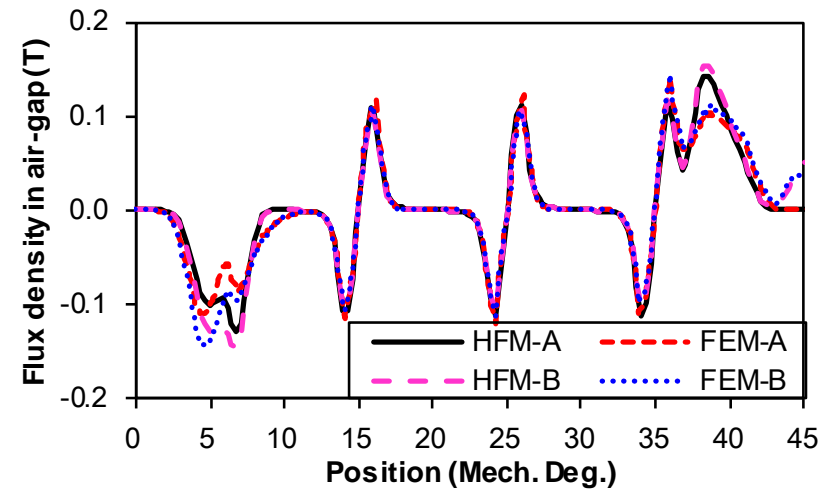

(b)

Fig. 8 Comparison of air-gap field distribution predicted by HFM and FEMin the 8-pole/36-slot motor: (a) radial component, (b) tangential component.

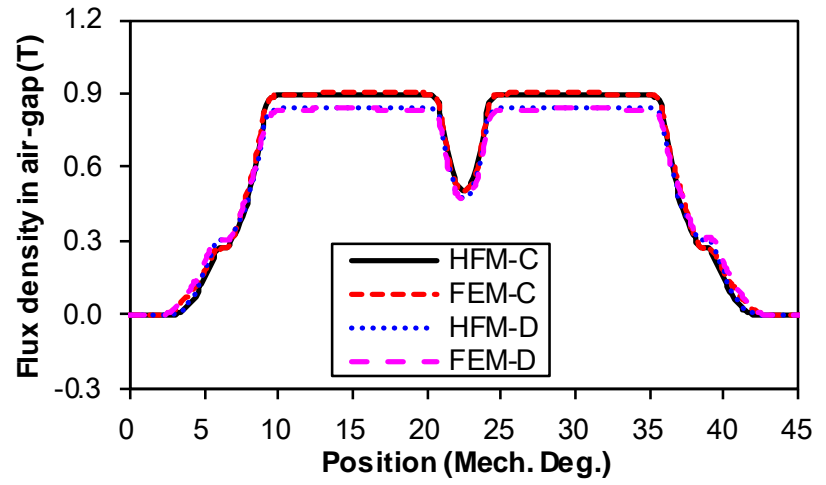

(a)

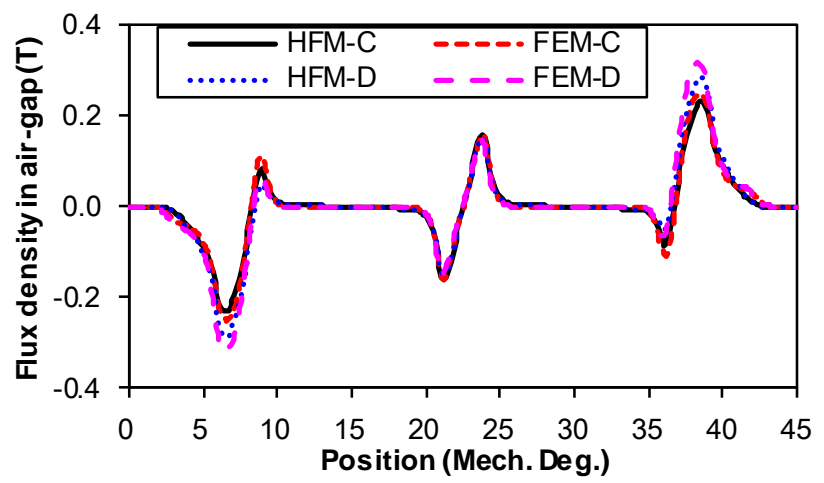

(b)

Fig. 9 Comparison of air-gap field distribution predicted by HFM and FEMin the 8-pole/24-slot motor: (a) radial component, (b) tangential component.

The HFM predicted flux linkage is compared with FEM results in Figs. 10-11. The HFM still has high accuracy in calculating the flux linkage. It is demonstrated that the saturation effect on the flux linkage can be analytically represented by HFM, which decrease the amplitude of the flux linkage. Fig. 12 gives the measured back-EMF to show great accuracy of the proposed model for Motor A. In addition, from Figs 13-15, the back-EMF predicted by HFM agrees well with FEM results, even though iron saturation is severe.

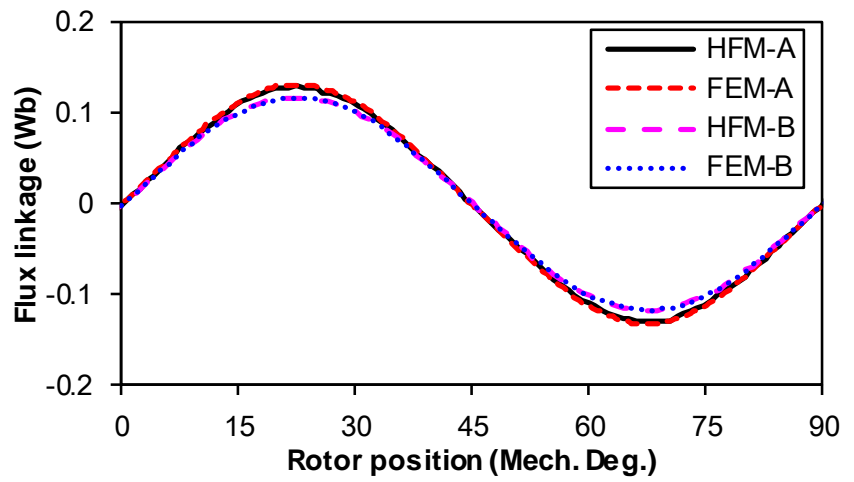

Fig. 10 Comparison of flux linkage predicted by HFM and FEM in the 8 pole/36-slot motor. 


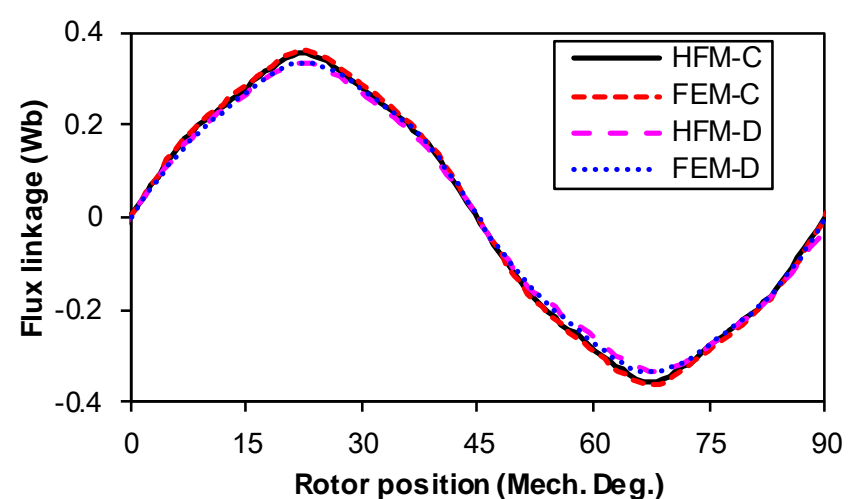

Fig. 11 Comparison of flux linkage predicted by HFM and FEM in the 8pole/24-slot motor.

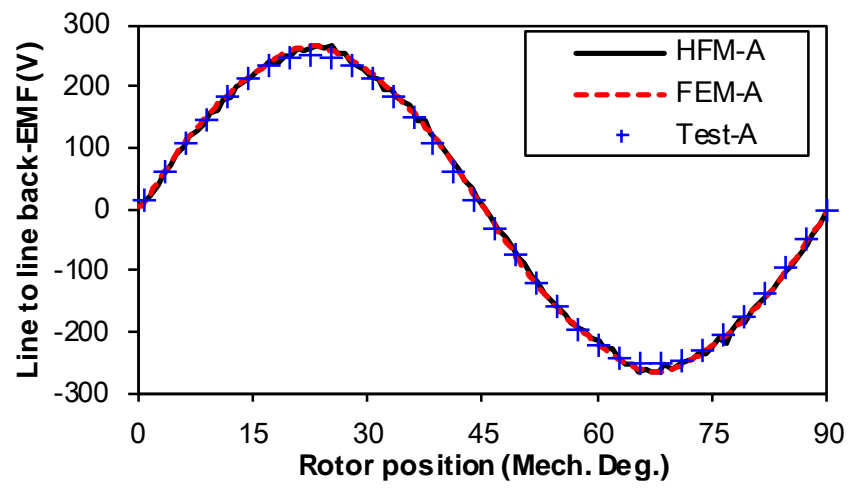

Fig. 12 Comparison of back-EMF obt ained from HFM, FEM, andexperiment for Motor A.

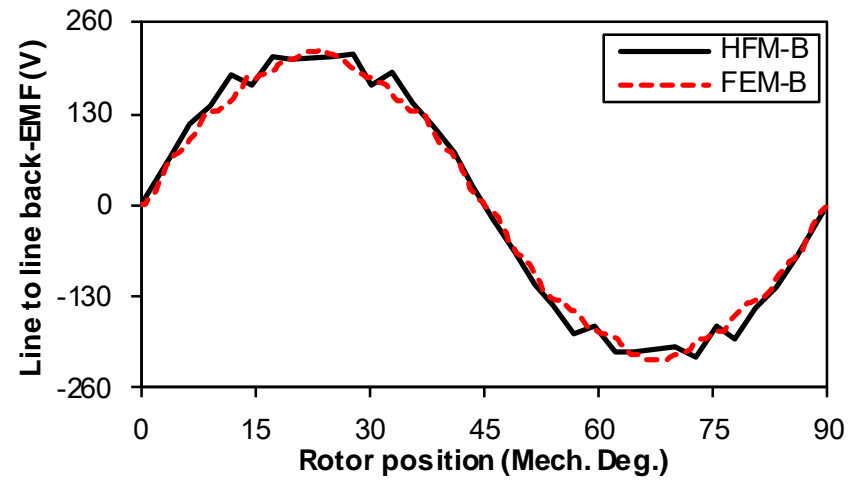

Fig. 13 Comparison of back-EMF obtained from HFM and FEM for Motor B.

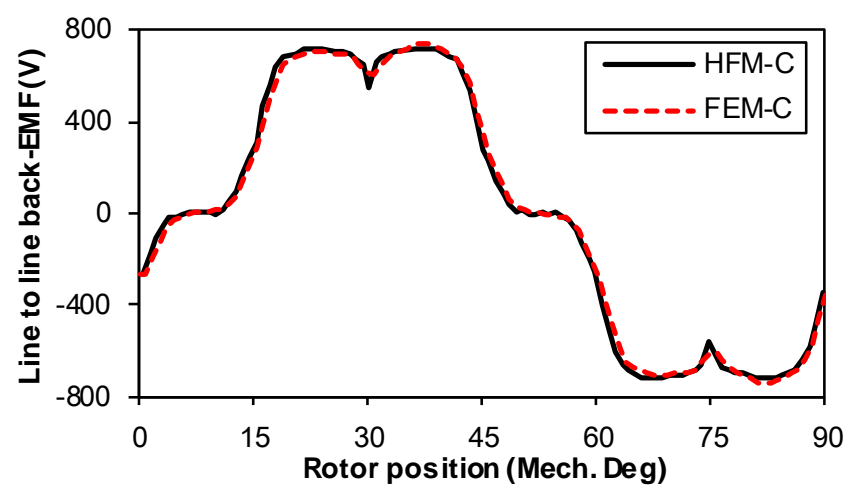

Fig. 14 Comparison of back-EMF obtained from HFM and FEM for Motor C.

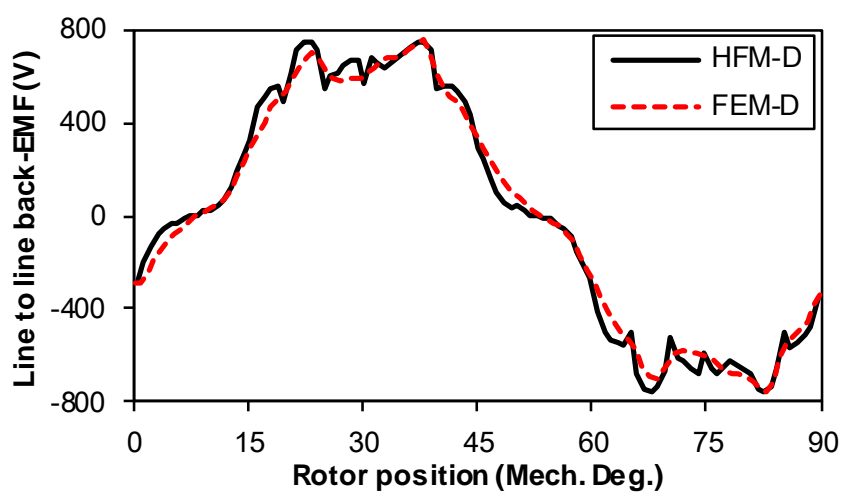

Fig. 15 Comparison of back-EMF obtained from HFM and FEM for Motor D.

\section{CONCLUSION}

This paper proposed a hybrid field model for calculating open-circuit field in IPM motors with V-type and conventional "." type rotor considering saturation effect. In the proposed HFM, the IPM and iron saturation are modelled as equivalent current on the rotor surface and stator bore. Thus, the MEC for calculating iron saturation and ECM for predicting slotted airgap field are associating with each other through the equivalent current. Iterative calculation is required to obtain the magnetic potential distribution of the iron region in only one loop. Then the equivalent current is determined for air-gap field prediction of IPM motors considering both slotting effect and saturation effect. Both FE analysis and experiment results verify the high accuracy of the proposed model.

\section{ACKNOWLEDGMENT}

This work was supported by the National Natural Science Foundation of China (51877196), Key R\&D Program of Zhejiang (2019C01075), Ningbo Innovation 2020 Program (20181ZDYF020129), and the Cao Guangbiao High Tech Development Fund of Zhejiang University.

\section{REFERENCES}

[1] L. J. Wu, Z. Q. Zhu, J. T. Chen, Z. P. Xia, and G. W. Jewell, "Optimal split ratio in fractional-slot interior permanent-magnet machines with non-overlapping windings," IEEE Trans. Magn., vol. 46,no.5,pp. 12351242, May 2010

[2] Q. Li, T. Fan, and X. Wen, "Armature-reaction magneticfieldanalysisfor interior permanent magnet motor based on winding function theory," IEEE Trans. Magn., vol.49, no. 3, pp. 1193-1201, March 2013.

[3] M. S. Mirazimi and A. Kiyoumarsi, "Magnetic field analysis of multiflux-barrier interior permanent-magnet motors through conformal mapping," IEEETrans. Magn., vol.53, no. 12,pp. 1-12, Dec. 2017.

[4] D.K. Lim, K.P. Yi, D.K. Woo, H.K. Yeo, J.S. Ro, C.G. Lee, and H.K. Jung, "Analysis and design of a multi-layered and multi-segmented interior permanent magnet motor by using an analytic method," IEEE Trans. Magn., vol.50, no. 6, pp. 1-8, June 2014.

[5] Z, Zhang, C. L. Xia, Y. Yan, Q. Geng, and T. Shi, "A hybrid analytical model for open-circuit field calculation of multilayer interiorpermanent magnet machines," J. Magn. Magn. Mater., vol. 435, pp. 136-145, 2017.

[6] L. Zhu, S. Z. Jiang, Z. Q. Zhu, and C. C. Chan, "Analytical modeling of open-circuit air-gap field distributions in mult isegment and multilayer interior permanent-magnet machines," IEEE Trans. Magn., vol.45,no.8, pp. 3121-3130, Aug. 2009

[7] C. Mi, M. Filippa, W. Liu, and R. Ma, "Analytical method for predicting the air-gap flux of interior-type permanent-magnet machines," IEEE Trans. Magn., vol. 40,no. 1, pp. 50-58, Jan. 2004. 
[8] K. Nakamura, K. Saito, T. Watanabe, and O. Ichinokura, "A new nonlinear magnetic circuit model for dynamic analysis of interior permanent magnet synchronous motor," J. Magn. Magn. Mater., vol. 290-291, pp. 1313-1317, 2005.

[9] X. Huang, M. Zhu, W. Chen, J. Zhang, and Y. Fang, "Dynamicreluctance mesh modeling and losses evaluation of permanent magnet traction motor," IEEE Trans. Magn., vol. 53, no. 6, Jun. 2017.

[10] W. Kemmetmüller, D. Faustner, and A. Kugi, "Modeling of apermanent magnet synchronous machine with internal magnets using magnetic equivalent circuits," IEEE Trans. Magn., vol. 50, no. 6, pp. 1-14, June 2014.

[11] H. Chen, D. Li, R. Qu, Z. Zhu, and J. Li, "An improved analyticalmodel for induct ance calculation of interior permanent magnet machines," IEEE Trans. Magn., vol.50, no.6, pp. 1-8, June 2014.

[12] P. Akiki, M.H. Hassan, J.C. Vannier, M. Bensetti, D. Prieto, B. Daguse and Mike McClelland, "Nonlinear analytical model for a multi-V-shape IPM with concentrated winding," IEEE Trans. Ind. Appl., vol. 54,no.3, pp. 2165-2174, May-June 2018.

[13] M. Farshadnia, M. A. M. Cheema, R. Dutta, and J. E. Fletcher,"Analytical modeling of armature reaction air-gap flux density consideringthenonhomogeneously saturated rotor in a fractional-slot concentrated-wound IPM machine," IEEE Trans. Magn., vol. 53, no. 2, pp. 1-12, Feb. 2017.

[14] F. R. Alam and K. Abbaszadeh, "Magnetic field analysis in eccentric surface-mounted permanent-magnet motors usinganimprovedconformal mapping method," IEEE Trans. Energy Convers., vol. 31,no.1,pp.333344, March 2016.

[15] K. Abbaszadeh andF. Rezaee Alam, "On-load field component separation in surface-mounted permanent-magnet motors using an improved conformal mapping method," IEEE Trans. Magn., vol.52,no.2,pp.1-12, Feb. 2016.

[16] A. Hanic, D. Zarko, and Z. Hanic, "A novel method for no-loadmagnetic field analysis of saturated surface permanent-magnet machines using conformal mapping and magnetic equivalent circuits," IEEE Trans. Energy Convers., vol. 31, no.2, pp. 740-749, Jun. 2016.

[17] A. Hanic, D. Zarko, D. Kuhinek, andZ. Hanic, "On-Load analysis of saturated surface permanent magnet machines using conformalmapping and magnetic equivalent circuits," IEEE Trans. Energy Convers.,vol.33, no. 3, pp. 915-924, Sept. 2018.

[18] L. J. Wu, Z. K. Li, X. Y. Huang, Y. L. Zhong, Y. T. Fang, and Z. Q. Zhu, "A hybrid field model for open-circuit field prediction in surface-mounted PM machines considering saturation," IEEE Trans. Magn., vol.54,no.6, pp. 1-12, June 2018 .

[19] K. Boughrara, R. Ibtiouen, D. Zarko, O. Touhami, and A. Rezzoug, "Magnetic field analysis of external rotor permanent-magnet synchronous motors using conformal mapping," IEEE Trans. Magn., vol.46,no.9,pp. 3684-3693, Sept. 2010.

[20] T. C. O'Connell and P. T. Krein, "A Schwarz-Christoffel-Based Analytical Method for Electric Machine Field Analysis," IEEE Trans. Energy Convers., vol. 24, no. 3, pp. 565-577, Sept. 2009.

[21] T. A. Driscoll, Schwarz-Christoffel Toolbox User's Guide: Version 2.3. Newark, DE: University of Delaware, 2005.

[22] B. Hague, Electromagnetic Problems in Electrical Engineering.London, U.K.: Oxford Univ. Press, 1929. 